\title{
On the surface energy budget of sea ice
}

\author{
Gerd Wendler, Ute Adolphs, Adrian Hauser, Blake Moore \\ Geophysical Institute, University of Alaska-Fairbanks, Fairbanks, Alaska 99775, U.S.A.
}

\begin{abstract}
The surface energy budget was investigated during a cruise through the pack ice in the Southern Ocean. The time of observation was close to mid-summer. Some of the more important findings were:
\end{abstract}

The mean albedo varied from $11 \%$ for open water to $59 \%$ for $10 / 10$ ice cover. Hourly values span the range from $6 \%$ (open water) to $76 \%$ (total ice cover).

The net heat flux into the ocean $(B)$ was on average $109 \mathrm{~W} \mathrm{~m}^{-2}$. If this energy were used solely for melting of sea ice, $30 \mathrm{~mm}$ could be melted each day.

For low surface albedos (ice concentration below 7/10), the net radiation increased with decreasing cloudiness. However, the opposite was the case for a high surface albedo.

The last point shows the importance of clouds on the surface energy budget. Not only should their presence or absence be known but also the reflectivity of the underlying surface, as it might change the net radiation in opposite ways.

\section{INTRODUCTION}

On 21 December 1994, USCGC Polar Star left from Hobart, Tasmania, for a trip to McMurdo, Antarctica, to open up the sound for tanker and other support ship traffic. $4 \mathrm{~d}$ after leaving (see Figure 1 for the routing), the first ice was seen, and on 26 December 1994 we visited Dumont d'Urville. The sea ice surrounding this French station was very extensive, the most severe we had seen on our occasional trips for more than a decade. The French supply ship, L'Astrolabe, had at that time been unable to reach the station and we stayed about 30 miles offshore and flew in by helicopter. During the next $4 \mathrm{~d}$, we serviced and installed the automatic weather stations (AWS) (Stearns and Wendler, 1988) in Terre Adélie and King George Land which are reporting over satellite. On 7 January 1995, the ship arrived at McMurdo Sound.

During the trip we carried out continuous surface energybudget measurements from the ship. For this, continuously recording instrumentation was used; furthermore, on a few occasions, radiative spot measurements were done directly on the ice for calibration purposes.

A short summary which gave some of the radiation characteristics as a function of surface albedo and cloudiness has been reported previously (Wendler and others, in press), while this paper deals with all energy fluxes.

\section{OBSERVATIONS, MEAN METEOROLOGIGAL CONDITIONS AND INSTRUMENTATION}

For the period 24 December 1994 to 6 January 1995 continuous radiative and meteorological measurements were carried out. On 25 December 1994, we reported the first ice. From that position, we went further south towards the coast in the Dumont d'Urville region (26 December 1994) and, after arriving there, turned towards the east along the coasts of Terre Adélie and King George Land. Finally, we arrived at the ice edge of McMurdo Sound on 2 January 1995 (see Fig. 1). Measurements within the sound were carried out through 6 January 1995. All data were recorded on a Campbell scientific data logger, model $21 \mathrm{X}$. They were sent over a serial port (9600 baud) to a Notebook computer. The data logger sampled twice a second; these data were averaged for $10 \mathrm{~min}$ intervals and the averaged values were stored on the Notebook. The standard deviations of pitch and roll were recorded during these intervals. We also

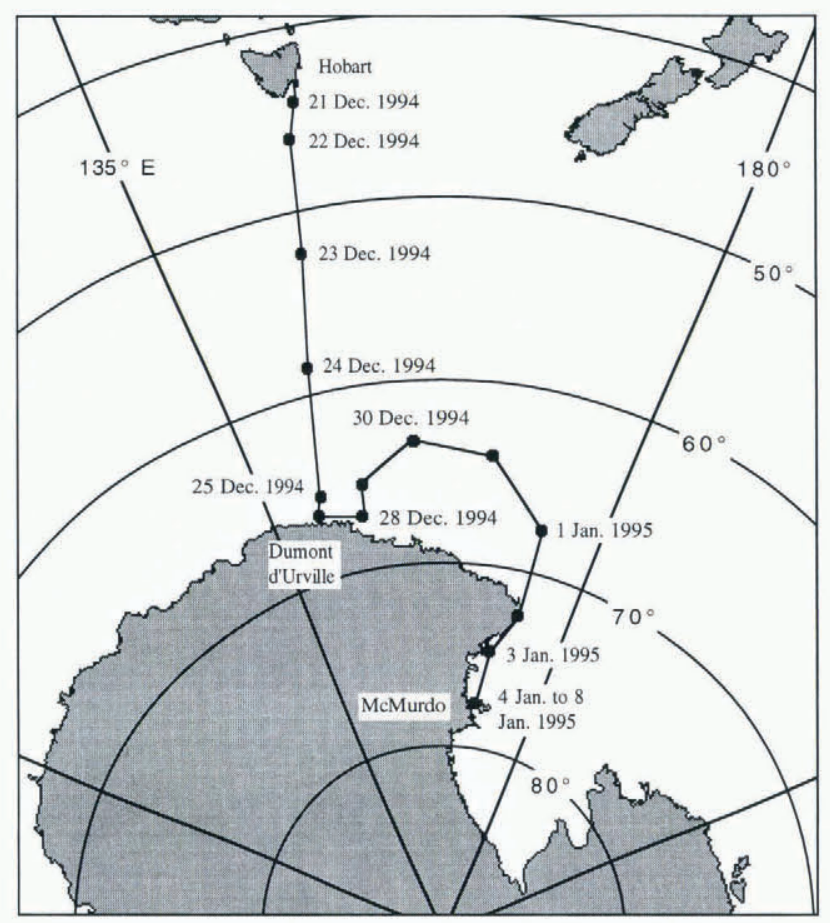

Fig. 1. The trip of USCGC Polar Star from Hobart, Tasmania, to McMurdo, Antarctica, during the voyage December 1994- January 1995. The numbers are the Julian days (position at midnight, GMT). 
used the Notebook to monitor all data during the entire cruise.

The mean meteorological conditions during this part of the cruise can be seen from Figure 2. On 24 December 1994, the air temperature (Fig. 2a) started out with $6^{\circ} \mathrm{C}$ but dropped rapidly. By 26 December 1994, when we were in the pack ice close to the Antarctic coast, air temperatures below the freezing point of salt water were observed. Thereafter, when going north to avoid heavy sea ice, it increased up to nearly $6^{\circ} \mathrm{C}$ and dropped again steadily until the arrival in McMurdo Sound.

The humidity (Fig. 2b) was high during the whole trip, typical for the marine environment. Mean values hovered around $68 \%$; actual values varied between $30 \%$ and $95 \%$. In general, it frequently had the tendency to display the opposite course of the temperature; early afternoon, which on average measured warmer temperatures, showed on average lower relative-humidity values than observed after midnight. The wind speed (Fig. 2c) was relatively low for this region of the world. Only during 4-6 January, strong winds with hourly average values of up to $22 \mathrm{~m} \mathrm{~s}^{-1}$ were observed.

The atmospheric pressure (Fig. 2d) displayed a minimum $(966 \mathrm{hPa})$ on 29 December 1994, a day on which rela- tively high wind speeds were observed. Radok and others (in press) compared the atmospheric pressure as measured on the ship with that displayed on synoptic maps of the area, and showed that, during the last 30 years, a substantial improvement in the quality of synoptic maps has occurred.

The global radiation and the reflected global radiation were measured with Eppley PSP pyranometers. These instruments have a nominal sensitivity of $9 \mu \mathrm{V} \mathrm{W} \mathrm{W}^{-1} \mathrm{~m}^{2}$ and are temperature-compensated. The cosine response is true to $1 \%$ for solar elevations of more than $20^{\circ}$ and $3 \%$ for solar elevations of $10-20^{\circ}$. They have a doubleWG7 clear-glass dome which is transparent for wavelengths of about 285 $2800 \mathrm{~nm}$. For the incoming and outgoing infrared radiation Epply model PIR pyrgeometers were used. These instruments have a nominal sensitivity of $3 \mu \mathrm{V} \mathrm{W}^{-1} \mathrm{~m}^{2}$. They have a $30 \mathrm{~mm}$ KRS 5 dome, which is transparent in the thermal infrared but not for global radiation. The temperature- dependence is small; it is within $2 \%$ for the whole range from $-20^{\circ}$ to $+40^{\circ} \mathrm{C}$ and cosine-response variations are insignificant for diffuse radiation.

The pitch and roll of the ship were measured with AccuStar clinometers built by Lucas Sensing Systems, Inc. They have a frequency response of $0.5 \mathrm{~Hz}$ and can be operated in



b
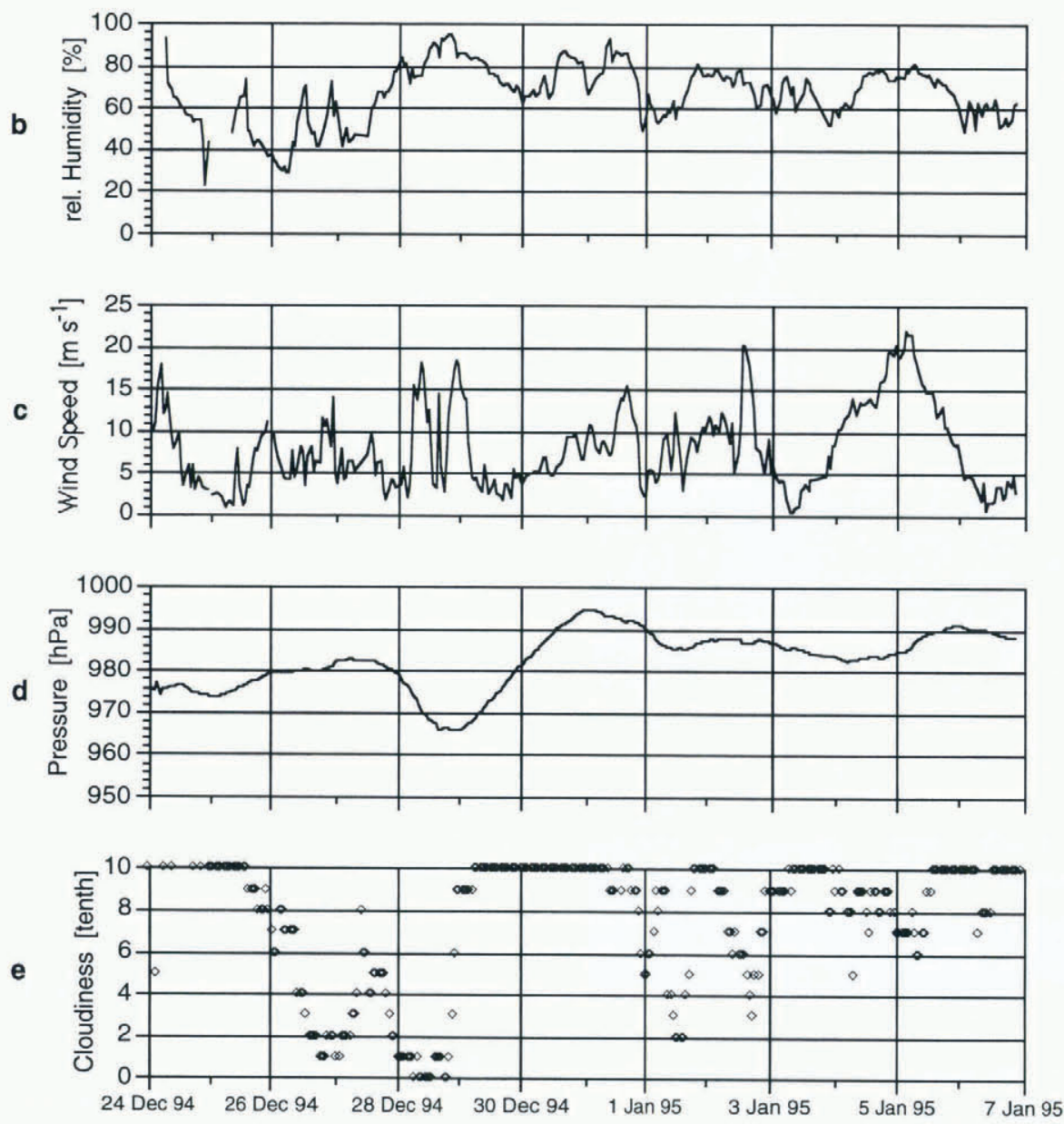

Fig. 2. Mean meteorological conditions during the cruise through the pack ice to McMurdo, 24 December 1994 to 6 January 1995. 
a temperature range between $-40^{\circ}$ and $+65^{\circ} \mathrm{C}$. For a tilt of less than $10^{\circ}$, the linearity is $0.1^{\circ}$, and for tilts of $10-45^{\circ}$ the linearity is within $1 \%$ of the tilt angle. The threshold and resolution are $0.001^{\circ}$ and the null repeatability is $0.05^{\circ}$.

The wind speed and direction were measured using a Met One wind-speed sensor model $014 \mathrm{~A}$ and a Met One winddirection sensor type 024A. The Met One wind-speed sensor has a measuring range of $0-45 \mathrm{~m} \mathrm{~s}^{-1}$, with an accuracy of $\pm 0.11 \mathrm{~m} \mathrm{~s}^{-1}$ or $1.5 \%$. The distance constant is less than $4.5 \mathrm{~m}$ and the starting threshold is $0.45 \mathrm{~m} \mathrm{~s}^{-1}$. The wind-direction sensor has an accuracy of $\pm 5^{\circ}$, a damping ratio of 0.25 and a delay distance less than $1.5 \mathrm{~m}$. The temperature-operation range for both instruments is $-50^{\circ}$ to $+70^{\circ} \mathrm{C}$. The atmospheric pressure was measured by a Paroscientific Digiquartz Pressure Transducer model 216B-101. This instrument has a repeatability and hysteresis of $\pm 0.003 \%$ and the operation range is $-54^{\circ}$ to $+55^{\circ} \mathrm{C}$. The temperature and the relative humidity were measured with Vaisala humidity and temperature probes, models HMP-35A and HMP-35D. The temperature sensor is a $\mathrm{Pt} 100 \mathrm{l} / 3$ DIN 43760B with an accuracy of $\pm 0.3^{\circ} \mathrm{C}$ at $20^{\circ} \mathrm{C}$. The humidity sensor is a Humicap $\mathrm{H}$-sensor, $0062 \mathrm{HM}$, with an accuracy at $20^{\circ} \mathrm{C}$ of $2 \%$ in the range $0-90 \%$ relative humidity and $3 \%$ in the range $90-$ $100 \%$. The temperature coefficient is $\pm 0.04 \%{ }^{\circ} \mathrm{C}^{-1}$ and the response time $(90 \%)$ is $15 \mathrm{~s}$. The operation range for both sensors is $-40^{\circ}$ to $+60^{\circ} \mathrm{C}$. For the surface temperature, a Telatemp Infrared Thermometer model AG-42 was used. It has an accuracy of $\pm 0.5^{\circ} \mathrm{C}$, the linearity is $\pm 0.3 \%$ of the full scale, the resolution is $\pm 0.1^{\circ} \mathrm{C}$ and the repeatability is $\pm 0.2^{\circ} \mathrm{C}$. The operation range is $-30^{\circ}$ to $+100^{\circ} \mathrm{C}$.

The instruments were installed on the fly-bridge of Polar Star (see Fig. 3), 32 m a.s.l. To measure the reflected global radiation and the outgoing longwave radiation, we used a boom extending over the side of the ship. We are aware that the ship wall affected the results of the reflected and longwave outgoing radiation. Direct spot measurements over the snowcovered sea ice showed that the ship-based reflectivity was on average $6 \%$ too low for $10 / 10$ ice cover. For open water, errors were small and no corrections were necessary; for the intervening ice concentration, linear interpolation was used for the corrections.

Errors in the longwave outgoing radiation were more difficult to correct for and they were mostly affected by the

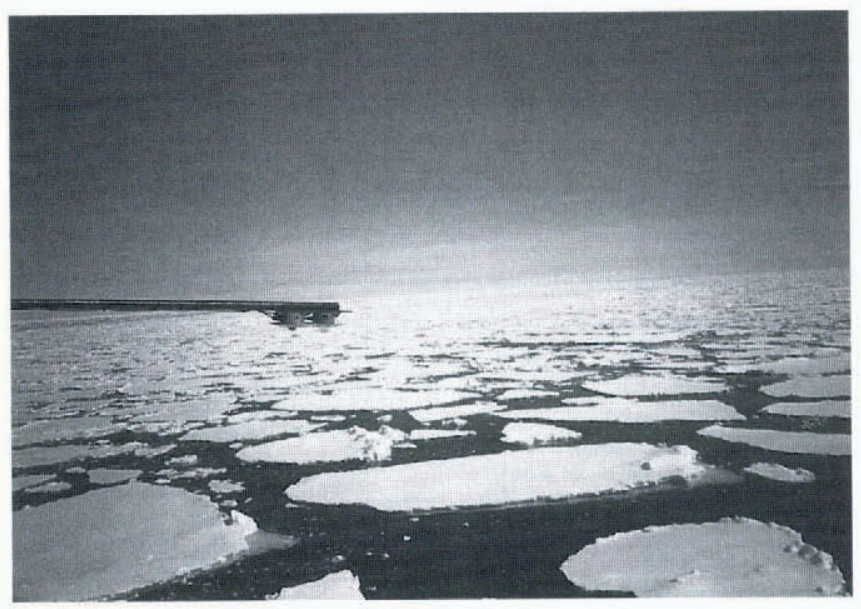

Fig. 3. Instruments for reflected shortwave radiation and longwave outgoing radiation mounted on a boom from the fly-bridge of USCGC Polar Star overlooking a broken seaice cover. presence of bright sunshine on the ship wall below the sensor. This resulted in too high a temperature when compared to the ocean or ice surface. In the absence of bright sunshine, errors were small; no corrections were carried out.

Our measured wind speeds had to be corrected for the movement of the ship. We were able to do this by using the GPS system.

The movement of the ship also influenced the other measurements, particularly those of the direct solar beam which affected most strongly the global radiation under clear-sky conditions. Hence, we made measurements of the pitch and roll. Wendler and Quakenbush (1994) showed that for hourly values no systematic deviations could be observed.

Hourly observations of the sea-ice concentrations were made visually by the MSTs (Marine Science Technicians) on board Polar Star. Furthermore, detailed ice measurements including thickness and type were carried out during the cruise by Newbury and Kirby (1995). A video camera looked vertically down from a side mount. Occasionally, broken ice flows were tipped and a scale within the video picture allowed the accurate determination of ice thickness. Furthermore, hourly visual observations of the cloud cover and type were also carried out by the MSTs.

\section{RESULTS}

\section{Radiation}

The radiation balance $(R B)$ of a surface is given by:

$$
R B=G(1-\alpha)+\left(L W_{\text {in }}-L W_{\text {out }}\right)
$$

with $G=$ the global radiation (sum of direct beam and diffuse radiation), $\alpha=$ the albedo, which is the ratio of reflected to incoming global radiation, $L W_{\text {in }}=$ the longwave incoming (thermal infrared) radiation, which is strongly dependent on the amount of fractional cloudiness, $L W_{\text {out }}=$ longwave outgoing radiation, which is a function of the surface temperature.

The first term of the righthand side of the equation is the shortwave radiation balance, which is naturally zero at night, and normally has its maximum around solar noon. The second term is the longwave radiation balance; it is normally negative as the surface radiates with a higher temperature than the atmosphere. It can become positive for shorter time periods, normally in connection with the advection of warm clouds. In contrast to the solar radiation, it does not display a strong diurnal variation. We measured these four fluxes independently of each other.

The mean diurnal variation of the global and reflected radiation is presented for the mean of the $14 \mathrm{~d}$ in Figure 4. The expected sinusoidal curves can be observed. Daily courses for individual days varied widely, depending mostly on the amount and type of cloud, and to a lesser degree on the position of the ship and atmospheric turbidity. A maximum mean daily value of $345 \mathrm{~W} \mathrm{~m}^{-2}$ was observed on 4 January 1995, a partly cloudy day; the minimum $\left(138 \mathrm{~W} \mathrm{~m}^{-2}\right.$ ) was observed on 24 December 1994, a day with a thick layer of stratus overcast. The mean daily global radiation was measured as $241 \mathrm{~W} \mathrm{~m}^{-2}$ and was strongly dependent on the amount of cloudiness. As we traveled over a large region during the cruise, changing the day length and solar elevations, we normalized the global radiation by dividing it by the extra-terrestrial radiation for that day and that position. The ratio $K_{\mathrm{T}}$ is the effective transmittance of 


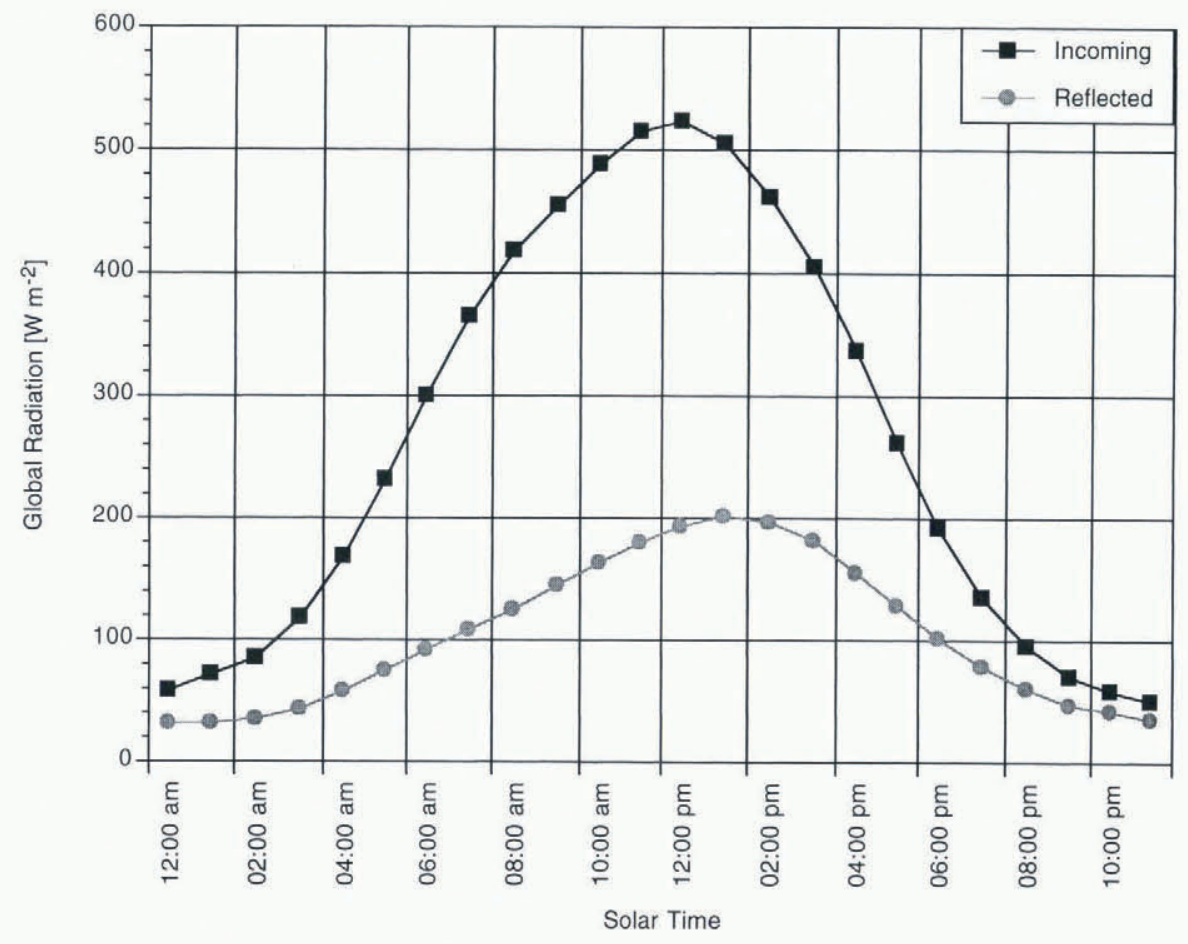

the atmosphere, also called the clearness index. It can be seen from Figure 5 that its value increases with decreasing cloudiness. There is a fair amount of scatter. This is caused by the fact that we did not distinguish between different cloud types; our data set was not large enough for doing so.

For open water, we found albedo values which varied between $6 \%$ and $14 \%$. The exact value depended on the solar elevation, the absence or presence of clouds and the sea state. The observed values are in agreement with the literature (e.g. Allison and others, 1993). The sea ice we experienced was normally snow-covered. Values of up to $76 \%$ were recorded as mean hourly values for 10/10 snow-covered sea ice. Spot measurements on the sea ice itself occasionally gave even higher values. The absolute maximum was $85 \%$, which is a value expected for dry snow of interior Antarctica. However, the value of up to $76 \%$, as measured from the ship, appears more reasonable. The difference might be explained by the fact that the radiative sensor on the ship integrated over larger areas and longer time periods.

In most cases, melting of the snow had occurred previously (these measurements were made after mid-summer), even if at the time of the observations below-freezing temperatures were observed. A melting event changes the snow-crystal structure, reducing the albedo through this process. Stratigraphic studies of the snow indicated this had occurred. In Figure 6, the ice concentration which was observed hourly is plotted against the reflectivity. It can be seen that the albedo increases with increasing ice concen-



Fig. 5. The clearness index $K_{\mathrm{T}}$ is plotled against fractional cloud cover $\left(r^{2}=0.73\right)$. Note the decrease of $K_{\mathrm{T}}$ with increasing cloudiness. The mean daily fractional cloud cover was binned in classes of $1 / 10$ cloud amount. 
tration. Ice concentrations and albedos were averaged for 2/ 10 ice-concentration classes. For open water, a mean value of about $11 \%$ was observed. This value is relatively high and was caused by the long time periods with low solar elevation during which the surface reflectivity is increased (Carroll, 1982). For 10/10 ice concentration, the mean albedo value was $59 \%$. The mean value for the albedo for the whole observational period was $39 \%$. The observed values are in agreement with those reported previously (Weller, 1968; Andreas and Makshtas, 1985; Allison and others, 1993; Hauser and others, in press).

While the albedo and, with it, the shortwave radiation budget is strongly influenced by the presence of sea ice, the longwave radiation budget is affected to a much smaller degree. The outgoing radiation is a function of the surface temperature; hence, the infrared losses from an ice-covered surface are always equal to or less than for sea water. There is only a very small diurnal variation of about $7 \mathrm{~W} \mathrm{~m}^{-2}$ following roughly the diurnal course of the air temperature (not shown). The mean value for the whole time period was $285 \mathrm{~W} \mathrm{~m}^{-2}$; assuming an emissivity of 0.97 , this would result in a surface temperature of the water or ice of $-4.9^{\circ} \mathrm{C}$. There was a tendency that the outgoing radiation decreased with increasing ice concentration (Table 1).

The incoming longwave radiation does not show any systematic diurnal variation, even for the average of the observational period. A mean value for the whole time period of $252 \mathrm{~W} \mathrm{~m}^{-2}$ was found. This is a relatively high value which is caused by the large amount of the observed fractional cloud cover; the incoming longwave radiation is strongly dependent on this amount. The mean value of the longwave radiation budget for the total observed period was found to be $-33 \mathrm{~W} \mathrm{~m}^{-2}$; the mean value for $10 / 10$ cloudiness was $-18 \mathrm{~W} \mathrm{~m}^{-2}$, while the losses more than tripled for clearsky conditions with an average value of $-67 \mathrm{~W} \mathrm{~m}^{-2}$. In Figure 7 the net longwave radiation is plotted against fractional cloudiness.

The all-wave radiation balance or net radiation is the sum of the short- and longwave radiation budgets. The glo-
Table 1. Mean outgoing longwave radiation and surface temperature for different sea-ice concentrations

Ice concentration
\begin{tabular}{ccc} 
Tenths \\
$0-4$ & $4-7$ & $7-10$ \\
\hline 292 & 287 & 276 \\
-3.2 & -4.4 & -7.0
\end{tabular}

Outgoing longwave radiation $\left(\mathrm{W} \mathrm{m}^{-2}\right)$

Temperature, assuming $\varepsilon=0.97\left({ }^{\circ} \mathrm{C}\right)$

bal radiation displays a strong diurnal variation, as can be seen from Figure 5, while the longwave radiation budget is fairly flat; hence, the net radiation also shows a strong diurnal variation following the shape of the global radiation. Maxima of about $300 \mathrm{~W} \mathrm{~m}^{-2}$ are observed around solar noon. At night, the values become negative for $4-5 \mathrm{~h}$ but are positive as a whole, as can be seen from Figure 8 . The averaged value is $115 \mathrm{~W} \mathrm{~m}^{-2}$. This is a substantial value and allows $30 \mathrm{~mm}$ of ice to be melted daily if all this energy were to be used for this purpose.

The shortwave radiation budget decreases with increasing ice concentration (can be deduced from Figure 6) (Grenfell, 1979) and the amount of cloudiness. On the other hand, the longwave radiation budget is fairly independent of the sea-ice concentration but the losses are reduced with increasing cloudiness (see Fig. 7). Hence, it can be seen that the amount of cloudiness has two effects on the net radiation: it decreases the shortwave incoming radiation but also reduces the losses in the longwave region by increasing the back radiation from the atmosphere. The effect of these two processes can be seen from Figure 9. When the surface albedo is low (ice concentration less than 7/10), the net radiation increases with decreasing cloudiness. This is a result we would expect from our experience in mid-latitudes, as we know that sunny days are on average warmer than cloudy ones. However, if the surface albedo is high (ice concentration above 7/10), the opposite occurs. This counter-intuitive

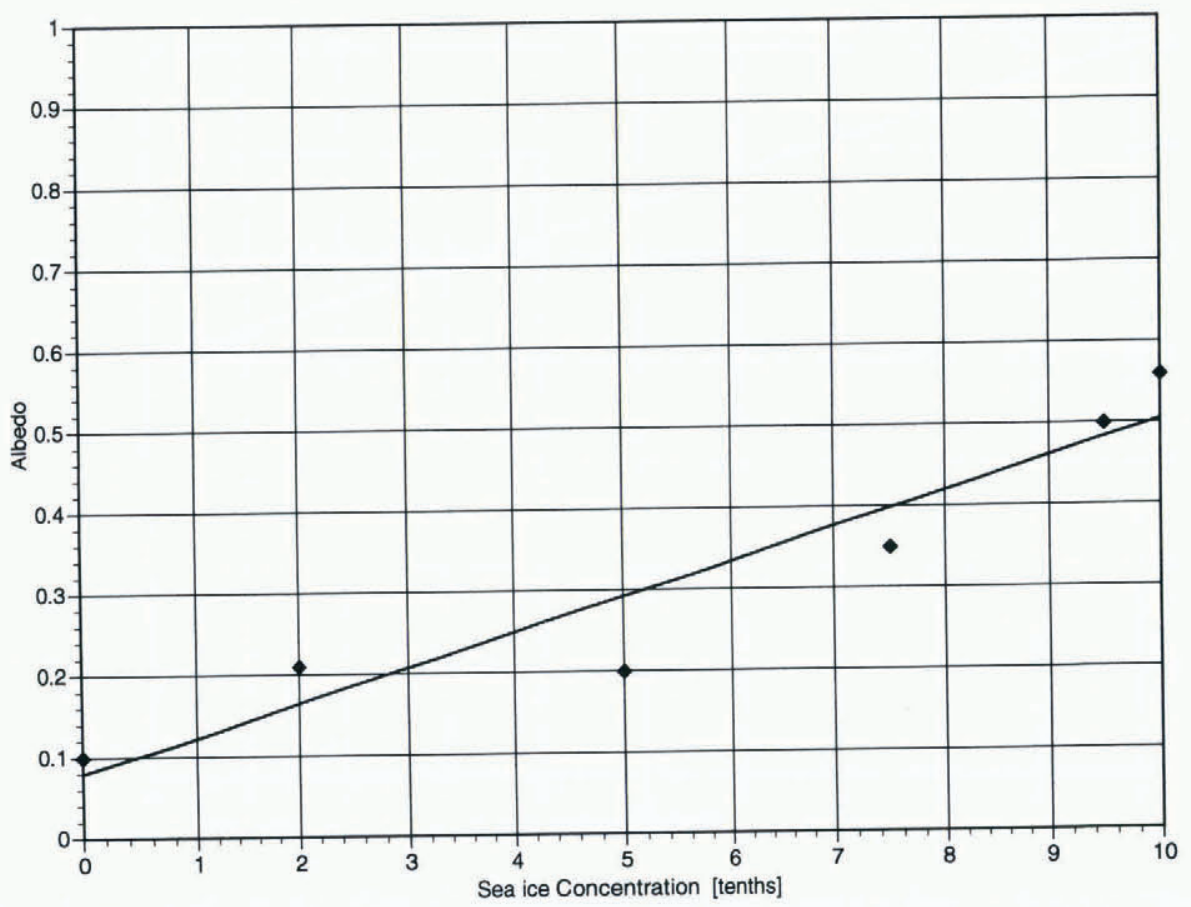

Fig. 6. The surface albedo as a function of ice concentration $\left(r^{2}=0.89\right)$. Values were averaged as a function of ice concentration. 


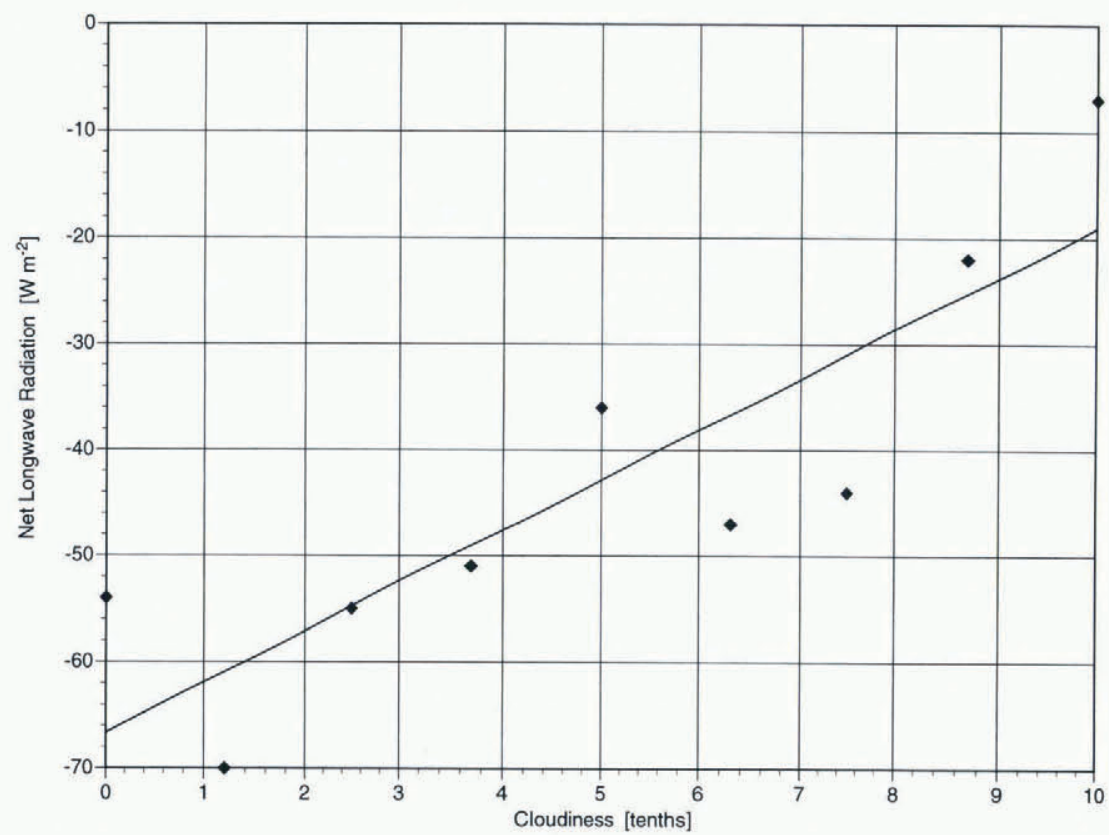

Fig. 7. The longwave radiation budget as a function of cloud amount $\left(r^{2}=0.76\right)$. Values were averaged as a function of fractional cloud cover.

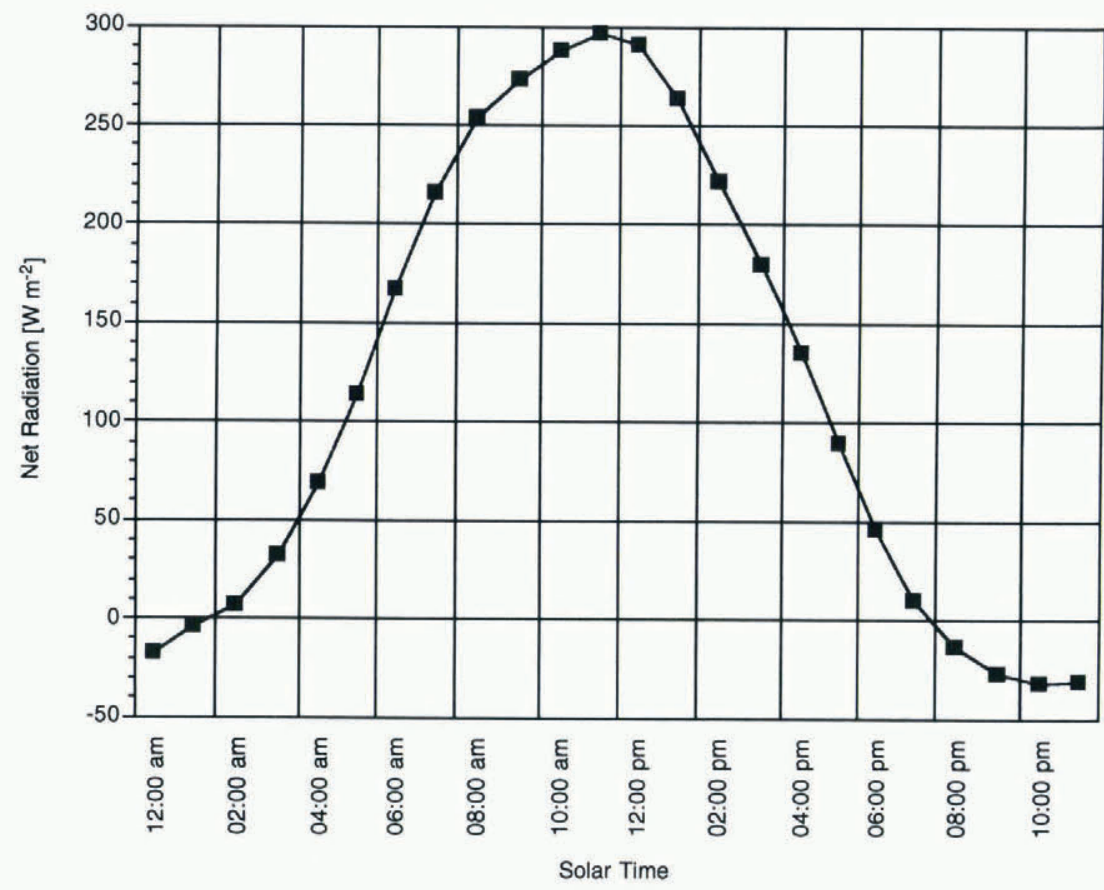

conclusion was first observed in Greenland by Ambach (1974), who coined the phrase "radiation paradox" for it. Due to the high surface albedo, most of the shortwave radiation is reflected back to space and the longwave radiation becomes the dominant parameter for the net radiation. These results again show the important influence of clouds on the surface energy budget. Not only should their presence or absence be known but also the reflectivity of the underlying surface, as it might change the net radiation in opposite ways.

\section{Turbulent fluxes}

To obtain the sensible $(S)$ and the latent $(L)$ heat fluxes, we used the gradient-flux method. The gradient-flux method is based on the Monin-Obukhov similarity theory (Businger and others, 1971). Engelbart (1989) compared the gradientflux method with the deposition-velocity method and the neutral bulk method. The gradient-flux method showed the best consistency to the measured $\overline{\left(w^{\prime} \theta^{\prime}\right)}$ or compared to the values computed with the Nieuwstadt (1978) method. To estimate the heat fluxes from the time-series data, the surface conditions were set to: $U\left(z_{0}\right)=0, \Theta\left(z_{0}\right)=T_{\mathrm{s}}$ and $Q\left(z_{0}\right)=Q_{\mathrm{s}}$. For the surface temperature, we used surface measurements made with an infrared thermometer.

With profiles depending on data from only the surface and one other level, the flux-gradient method is essentially a bulk-aerodynamic computation in which the bulk-transfer 


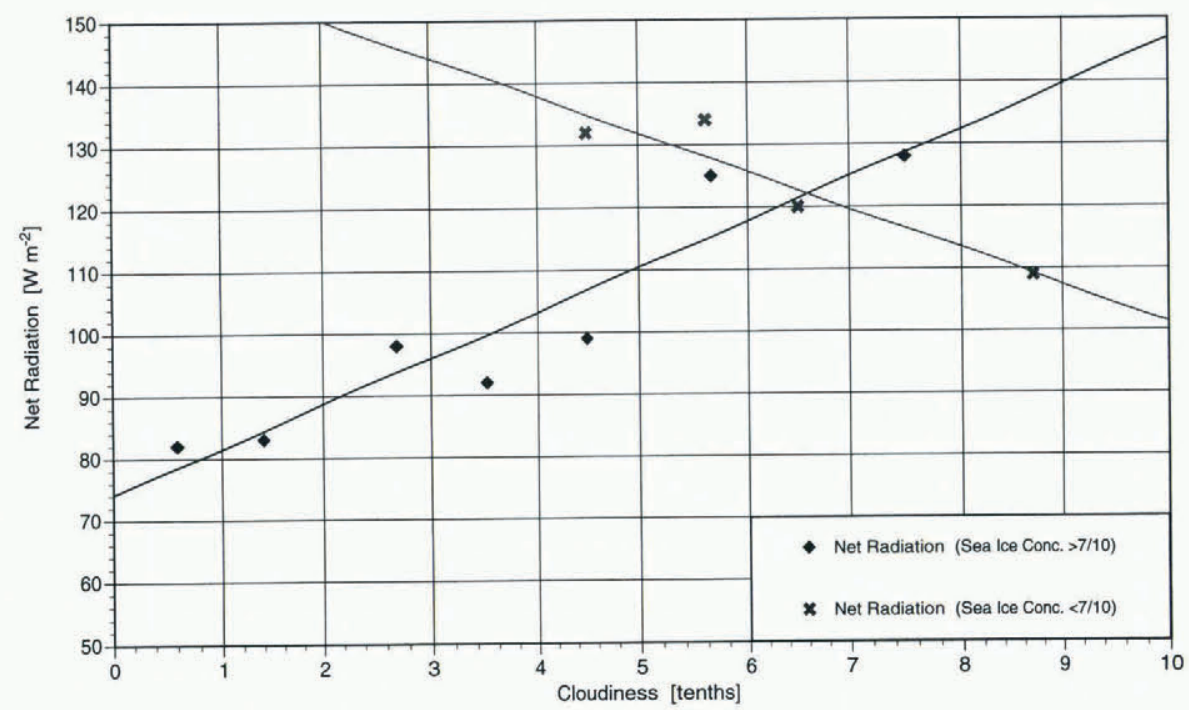

Fig. 9. The net radiation as a function of cloudiness $\left(r^{2}(<7 / 10)=0.86 . r^{2}(>7 / 10)=0.88\right)$. Values were averaged as a function of fractional cloud cover. The net radiation increases with decreasing cloud amount for the low surface reflectivity conditions $(<7 / 10$ ice concentration). For a high reflecting surface (>7/10 ice concentration), it decreases with decreasing cloudiness.

coefficient for heat $\left(C_{\mathrm{H}}\right)$ and moisture $\left(C_{\mathrm{E}}\right)$ are specified:

$$
\begin{aligned}
& S=C_{\mathrm{H}} \rho c_{\mathrm{p}} U(z)\left(T_{\mathrm{s}}-\Theta(z)\right) \\
& L=C_{\mathrm{E}} \rho L_{\mathrm{v}} U(z)\left(Q_{\mathrm{s}}-Q(z)\right) .
\end{aligned}
$$

This implies that for neutral stability, when $z_{0}=1 \times$ $10^{-3} \mathrm{~m}$ is used as the roughness parameter, the transfer coefficients are $C_{\mathrm{D}}=C_{\mathrm{H}}=C_{\mathrm{E}}=5.1 \times 10^{-4} ; C_{\mathrm{D}}$ is the drag coefficient. To estimate the fluxes, the minimum parameters needed are the wind speed $(U)$, the potential temperature $(\Theta)$ and the specific humidity $(Q)$ of two different heights. The profiles are fitted with the models:

$$
\begin{aligned}
& U(z)=\frac{u_{*}}{k}\left[\ln \frac{z}{z_{0}}-\psi_{\mathrm{m}} \frac{z}{L}\right] \\
& \Theta(z)=T\left(z_{\mathrm{s}}\right)+t_{*}\left[\ln \frac{z}{z_{\mathrm{s}}}-\psi_{\mathrm{h}} \frac{z}{L}\right] \\
& Q(z)=Q\left(z_{\mathrm{s}}\right)+q_{*}\left[\ln \frac{z}{z_{\mathrm{s}}}-\psi_{\mathrm{h}} \frac{z}{L_{\mathrm{Q}}}\right]
\end{aligned}
$$

with $z=$ height, $z_{0}=$ roughness length for velocity, $z_{\mathrm{s}}=$ scalar-roughness length, $T\left(z_{\mathrm{s}}\right)=$ surface temperature, $Q\left(z_{\mathrm{s}}\right)=$ surface humidity, $k(=0.4)=$ von Kármán's constant, $\psi=$ semi-empirical Monin-Obukhov similarity functions, $\psi$ are functions of the stability parameter $\zeta\left(=z / L\right.$ or $\left.z / L_{\mathrm{Q}}\right)$. The functions are different for stable and unstable conditions:

Unstable conditions $(\zeta<0)$ (Paulson, 1970):

$$
\begin{aligned}
\psi_{\mathrm{m}}(\zeta) & =2 \ln \left[\frac{1+x}{2}\right]+\ln \left[\frac{1+x^{2}}{2}\right]-2 \arctan (x)+\frac{\pi}{2} \\
\psi_{\mathrm{h}}(\zeta) & =2 \ln \left[\frac{1+x^{2}}{2}\right] \quad \text { and } \\
x & =\left(1-\beta_{\mathrm{u}} \zeta\right)^{\frac{1}{4}} .
\end{aligned}
$$

Stable/neutral conditions $(\zeta \geq 0)$ (Webb, 1970) give:

$$
\psi_{\mathrm{m}}(\zeta)=\psi_{\mathrm{h}}(\zeta)=-\beta_{\mathrm{s}} \zeta
$$

with $\beta_{u}=16, \beta_{\mathrm{s}}=7$ (Large and Pond, 1982).

$u_{*}, t_{*}$ and $q_{*}$ are related to the surface stress $(\tau)$, the sensible
$(S)$ and the latent $(L)$ heat fluxes, and thus link these to the measured profiles:

$$
\begin{aligned}
& u_{*}=(\tau / \rho)^{\frac{1}{2}} \\
& t_{*}=-S /\left(\rho c_{\mathrm{p}} u_{*} k\right) \\
& q_{*}=-L /\left(\rho L_{\mathrm{v}} u_{*} k\right)
\end{aligned}
$$

with $\rho=$ surface air density, $c_{\mathrm{p}}=$ specific heat of air at constant pressure, $L_{\mathrm{v}}=$ latent heat of vaporization (sublimation) of water (ice).

Finally, the Obukhov lengths, $L$ and $L_{\mathrm{Q}}$, both are stability parameters:

$$
\begin{aligned}
L & =\left\{\left[\frac{\bar{T}}{g} \frac{u_{*}{ }^{2}}{k^{2} t_{*}}\right]^{-1}+L_{\mathrm{Q}}{ }^{-1}\right\}^{-1} \\
L_{Q} & =\frac{1}{g}\left[\frac{1+0.61 \bar{Q}}{0.61}\right] \frac{u_{*}{ }^{2}}{k^{2} q_{*}}
\end{aligned}
$$

with $g=$ acceleration of gravity, $\bar{T}=$ representative temperature.

Notice $L$ is used as a stability parameter for temperature and velocity, $L_{\mathrm{Q}}$ for humidity. McBean (1971) explained that unless a passive scalar, such as humidity, is highly correlated with temperature, $L$ is not a proper scaling length (Dyer, 1974). A length scale based on the flux of a passive scalar alone, such as $L_{\mathrm{Q}}$, is instead a more meaningful parameter.

In our case, variables were measured at two heights only: the surface and the reference height, $32 \mathrm{~m}$. For the surface values, we assume $z_{0}=z_{\mathrm{s}}$. A problem was to assume a fairly realistic value for the roughness parameter $z_{0}$, which can vary over a wide range. Belitz and others (1987) found values from $1 \times 10^{-6} \mathrm{~m}$ for extremely smooth ice up to $1.5 \times 10^{-2} \mathrm{~m}$ for wavy drift ice. Engelbart (1989) and Andreas and Makshtas (1985) found even greater maximum values. König (1985) measured a mean value of $z_{0}=1 \times$ $10^{-4} \mathrm{~m}$ on Ekströmisen. An ice shelf is generally smoother than normal sea ice. We assumed $z_{0}=1 \times 10^{-3} \mathrm{~m}$ (Banke and others, 1980). With only two heights, the profile equations are particularly simple: 


$$
\begin{aligned}
u_{*} & =\frac{k U_{30}}{\ln \left(30 / z_{0}\right)-\psi_{\mathrm{m}}(30 / L)}, \\
t_{*} & =\frac{\Theta_{30}-T_{\mathrm{s}}}{\ln \left(30 / z_{0}\right)-\psi_{\mathrm{h}}(30 / L)}, \\
q_{*} & =\frac{Q_{30}-Q_{\mathrm{s}}}{\ln \left(30 / z_{0}\right)-\psi_{\mathrm{h}}\left(30 / L_{\mathrm{Q}}\right)}
\end{aligned}
$$

with $Q_{\mathrm{s}}=$ specific humidity of air in saturation and $T_{\mathrm{s}}=$ surface temperature.

The gradient-flux estimation procedure is an iterative one. First, neutral stability is assumed so that $\psi_{\mathrm{m}}=$ $\psi_{\mathrm{h}}=0$. This yielded initial values of $u_{*}, t_{*}$ and $q_{*}$ which we then used to estimate $L$ and $L_{\mathrm{Q}}$. With these first estimates of $L$ and $L_{\mathrm{Q}}$, the effects of stability by computing the $\psi$ values to use in the model equations could begin. New and better estimates of $u_{*}, t_{*}$ and $q_{*}$ are the results. With these values, recomputation of $L$ and $L_{\mathrm{Q}}$ were made. Three iterations were performed until the absolute changes in sensible $(S)$ and latent $(L)$ heat fluxes were all less than $0.1 \mathrm{~W} \mathrm{~m}^{-2}$ between consecutive iterations.

Figure 10 shows the time series of the computed sensibleand latent-heat flux. Positive values represent a flux downwards from the air to the surface. A positive flux is an energy gain for the surface. The sensible-heat flux was mostly positive with a maximum of $40 \mathrm{~W} \mathrm{~m}^{-2}$ and a minimum of $-18 \mathrm{~W} \mathrm{~m}^{-2}$, giving an average value of only $11 \mathrm{~W} \mathrm{~m}^{-2}$. The latent-heat flux was more variable with values between -91 and $27 \mathrm{~W} \mathrm{~m}^{-2}$; the average was $-17 \mathrm{~W} \mathrm{~m}^{-2}$.

\section{Surface energy budget}

The energy budget of a surface can be written as:

$$
B=R B+S+L \text {. }
$$

$B$ is the flux into or out of the ocean. It might be used for phase change (melting of ice or freezing of water) or storage change (change of temperature of sea ice or water). In Figure 11, the fluxes are presented. It can be seen that the net radiation $(R B)$ is the most important energy source in the budget $\left(115 \mathrm{~W} \mathrm{~m}^{-2}\right)$. The sensible- $(S)$ and latent-heat $L$ fluxes are of the same magnitude $\left(11\right.$ and $\left.-17 \mathrm{~W} \mathrm{~m}^{-2}\right)$ but have opposite directions. Assuming the sum of the sources and sinks to be $100 \%$, the main source is net radiation $(+91 \%)$, followed by the sensible-heat flux $(+9 \%)$, while sinks are the heat flux into the ocean $(-87 \%)$ and the latent flux $(-13 \%)$. The signs of the fluxes were to be expected for a time period close to mid-summer when the sea ice starts to disintegrate around Antarctica. If all energy were to be used for the melting of sea ice, daily $30 \mathrm{~mm}$ of ice could be melted, which is a relatively large value.

The question arises as to how our results agree or disagree with other studies. Such a comparison is difficult, because there are no complete energy balances for partly icecovered oceans close to mid-summer. Gordon (1981) gave the average monthly heat flux into the ocean for partial ice $(3 / 10)$ cover as $65 \mathrm{~W} \mathrm{~m}^{-2}$ for January, which is smaller than our flux of $109 \mathrm{~W} \mathrm{~m}^{-2}$.

Similar results to our radiation balance were obtained by Andreas and Ackley (1982); they measured at $70^{\circ} \mathrm{S}$ on 1 December. The greatest difference is in the shortwave radiation balance caused by different albedo values; it should be borne in mind that we measured over a large area 65 $78^{\circ} \mathrm{S}$ ) with ice concentrations ranging from 0 to $10 / 10$.

Heinemann and Rose (1990) made measurements in February 1984 near Filchner Station on the ice shelf; however, the conditions on an ice shelf are completely different. The radiation balance reached a daily average value of $-20 \mathrm{~W} \mathrm{~m}^{-2}$ due to the much higher albedo values.

Andreas and Makshtas (1985) and Hauser and others (in press) made measurements in spring. They found smaller fluxes, a result to be expected as the solar radiation is much weaker. Andreas and Makshtas (1985) measured the flux into the ocean as $20-25 \mathrm{~W} \mathrm{~m}^{-2}$ while Hauser and others (in press) reported a flux of $30.7 \mathrm{~W} \mathrm{~m}^{-2}$.

A positive sensible-heat flux was also observed by Allison and others (1982); they showed that for a few weeks in January



Fig. 10. Time series of the sensible-and latent-heat flux, 24 December 1994 to 6 January 1995. Note, that the sensible-heat flux is on average positive; the air warms the surface. The latent-heat flux is on average negative; evaporation is more prevalent than
condensation. 


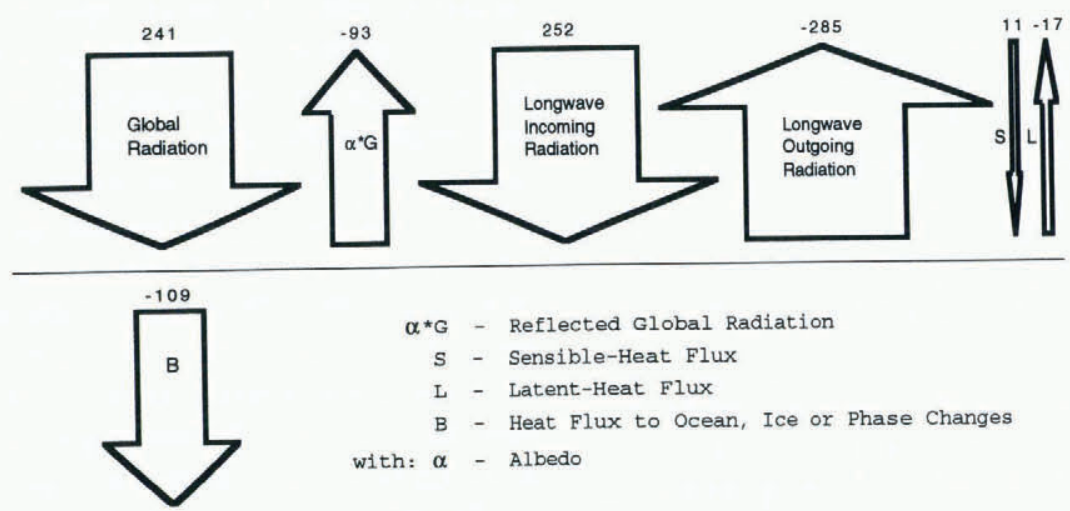

Fig. 11. Mean radiative and eddy fluxes, Southern Ocean, 24 December 1994 to 6 January 1995. Note the dominance of the radiative fluxes. The remainder of all atmospheric fluxes was assumed to be the flux for warming or melting of snow or ice.

the surface may gain energy by sensible-heat transfer but, by mid-February, the surface loses sensible heat throughout the day; the mean loss can be up to $100 \mathrm{~W} \mathrm{~m}^{-2}$

\section{ACKNOWLEDGEMENTS}

The research was supported by U.S. National Science Foundation grant OPP 94-13879. Captain Parsons and all the crew of Polar Star supported us wonderfully. Further, the helicopter detachment under LTCM Kayler was very helpful. J. Cassano and M. Seefeldt, University of Wisconsin, serviced/installed the AWS, and R. Summerson (Australian Antarctic Division) and B. Rabus (University of Alaska) participated in other aspects of our investigations. Dr G. Weller and J. Curtis improved the manuscript. To all of them go our sincere thanks.

\section{REFERENCES}

Allison, I., C. M. Tivendale, G. J. Akerman, J. M. Tann and R. H. Wills. 1982. Seasonal variations in the surface energy exchanges over Antarctica sea ice and coastal waters. Ann. Glaciol., 3, 12-16.

Allison, I., R. E. Brandt and S. G. Warren. 1993. East Antarctic sea ice: albedo, thickness distribution, and snow cover. f. Geophys. Res., 98(C7), $12,417-12,429$.

Ambach, W. 1974. The influence of cloudiness on the net radiation balance of a snow surface with high albedo. 7. Glaciol., 13 (67), 73-84.

Andreas, E. L. and S. F. Ackley. 1982. On the differences in ablation seasons of Arctic and Antarctic sea ice. J. Atmos. Sci., 39(2), $440-447$.

Andreas, E. L. and A. P. Makshtas. 1985. Energy exchange over Antarctic sea ice in the spring. J. Geophys. Res., 90(C4), 7199-7212.

Banke, E. G., S. D. Smith and R. J. Anderson. 1980. Drag coefficients at AIDJEX from sonic anemometer measurements. International Association of Hydrological Sciences Publication 124 (Symposium at Seattle 1977 Sea Ice Processes and Models), 430-442.

Belitz, H. -J., C. Kottmeier, R. Hartig and H. -U. Stuckenberg. 1987. Zur aerodynamischen Rauhigkeit arktischer Meereisflächen. Meteorol. Rundsch., 40(4), 97-107.

Businger, J. A., J. C. Wyngaard, Y. Izumi and E. F. Bradley. 1971. Flux-profile relationships in the atmospheric surface layer. 7. Atmos. Sci., 28, 181189.
Carroll, J.J. 1982. Long-term means and short-term variability of the surface energy balance components at the South Pole. 7. Geophys. Res., 87 (C6), 4277-4286.

Dyer, A. J. 1974. A review of flux-profile relationships. Boundary-Layer Meteorol., 7, 363-372.

Engelbart, D. 1989. Der turbulente Strom fühlbarer Wärme im Einflußbereich antarktischer Küstenpolynyen. Meteorol. Rundsch., 41 (4), 111-121.

Gordon, A. L. 1981. Seasonality of Southern Ocean ice. f. Geophys. Res., 86 (C5), 4193-4197.

Grenfell, T. C. 1979. The effects of ice thickness on the exchange of solar radiation over the polar oceans. f. Glaciol., 22(87), 305-320.

Hauser, A., G. Wendler, U. Adolph and M. Jeffries. In press. Energy exchange in early spring over sea ice in the Pacific sector of the Southern Ocean. J. Geophys. Res.

Heinemann, G. and L. Rose. 1990. Surface energy balance, parameterisations of boundary-layer heights and the application of resistance laws near an Antarctic ice shelf front. Boundary-Layer Meteorol., 51, 123-158.

König, G. 1985. Roughness length of an Antarctic ice shelf. Polarforschung, $55(1), 27-32$.

Large, W. G. and S. Pond. 1982. Sensible and latent heat flux measurements over the ocean. 7. Phys. Oceanogr., 12, 464-482.

McBean, G. A. 1971. The variations of the statistics of wind, temperature and humidity fluctuations with stability. Boundary-Layer Meteorol., 1, 438-457.

Newbury, G. S. and C. Kirby. 1995. Ice measurements in support of propeller load evaluation on the USCGC Polar Star in the Antarctic summer environment. St. John's, Nfld, National Research Council of Canada. Institute for Marine Dynamics. (IMD Test Report TR-1995-15.)

Nieuwstadt, F.T. M. 1978. The computation of the friction velocity $\mathrm{u}_{*}$ and the temperature scale $T$ * from temperature and wind velocity profiles by least-square methods. Boundary-Layer Meteorol., 14, 235-246.

Paulson, C. A. 1970. The mathematical representation of wind speed and temperature profiles in the unstable atmospheric surface layer. $\mathcal{F}$. Appl. Meteorol., 9, 857-861.

Radok, U., C. A. Smith and G. Wendler. In press. Southern Ocean synoptics - observation and analyses. Antarct. Sci.

Stearns, C. and G. Wendler. 1988. Research results from Antarctic automatic weather stations. Rev. Geophys., 26(1), 45-6l.

Webb, E. K. 1970. Profile relationships: the log-linear range, and extensions to strong stability. Q. F. R. Meteorol. Soc., 96, 67 90.

Weller, G.E. 1968. The heat budget and heat transfer processes in Antarctic plateau ice and sea ice. A.NARE Sci. Rep., Ser. A(4). Glaciol. 102.

Wendler, G. and T. Quakenbush. 1994. Ultraviolet radiation and its extinction in Antarctic sea ice. Antarct. J. U.S., 28 (5), 84-85.

Wendler, G., U. Adolph and B. Moore. In press. On the radiative characteristics in the Southern Seas. Antarct. F. U.S. 